\title{
Thermal Stability and Mechanism of Thermally Induced Crystallization of $\mathrm{Fe}_{73.5} \mathrm{Cu}_{1} \mathrm{Nb}_{3} \mathrm{Si}_{15.5} \mathrm{~B}_{7}$ Amorphous Alloy
}

\author{
M.M. VAsićc ${ }^{a}$, D.M. Minić ${ }^{b}$, V.A. BlagojeviĆc ${ }^{c}$, T. ŽÁK ${ }^{d}$, N. Pizúrová ${ }^{d}$, B. David ${ }^{d}$ \\ AND D.M. Miniće,*
}

${ }^{a}$ Faculty of Physical Chemistry, University of Belgrade, Belgrade, Serbia

${ }^{b}$ Military Technical Institute, Belgrade, Serbia

${ }^{c}$ Institute of Technical Sciences of Serbian Academy of Sciences and Arts, Belgrade, Serbia

${ }^{d}$ Institute of Physics of Materials, Academy of Sciences of Czech Republic, Brno, Czech Republic

${ }^{e}$ Department of Biochemical Sciences, State University in Novi Pazar, Novi Pazar, Serbia

\begin{abstract}
Investigation of thermal stability of the alloy revealed stepwise crystallization process, manifested by two distinct complex exothermic peaks in differential scanning calorimetry curves. Kinetic parameters of individual crystallization steps were found using the Kissinger and Vyazovkin methods. Structural characterization of thermally treated samples showed formation of different iron-based phases including $\alpha-\mathrm{Fe}(\mathrm{Si}), \mathrm{Fe}_{2} \mathrm{~B}, \mathrm{Fe}_{16} \mathrm{Nb}_{6} \mathrm{Si}_{7}$ and $\mathrm{Fe}_{2} \mathrm{Si}$ and some metastable intermediary species. Morphology characterization of the surface and cross-section of the thermally treated samples showed granulated structure composed of several different phases and indicated occurrence of impingement effects during crystal growth. Value of estimated lifetime suggested very high stability against crystallization at room temperature and abrupt decrease of lifetime with temperature increase.
\end{abstract}

DOI: 10.12693/APhysPolA.128.657

PACS: 64.70.dg, 64.70.kd, 64.70.pe

\section{Introduction}

Multicomponent iron-based amorphous alloys (metallic glasses) have been widely examined in the last fifty years, due to their favorable functional properties including high corrosion resistance, good mechanical and electrical properties, good soft magnetic properties [13]. Thermodynamic metastability makes them susceptible to microstructural changes under certain condition, such as high pressure and high temperature, or prolonged usage at moderate temperature. These microstructural changes include relaxation, crystallization and recrystallization processes, leading to deterioration or improvement of the functional properties.

Amorphous $\mathrm{Fe}_{73.5} \mathrm{Cu}_{1} \mathrm{Nb}_{3} \mathrm{Si}_{13.5} \mathrm{~B}_{9}$ alloy was the first metallic glass which served as precursor for preparation of nanocrystalline material with magnetic properties superior to those of fully amorphous and fully crystalline samples [4]. Presence of $\mathrm{Cu}$ and $\mathrm{Nb}$ atoms was found to be crucial for nanocrystallization [5-7]. $\mathrm{Cu}$ increases nucleation rate forming clusters with near-fcc symmetry, on whose surface $\alpha-\mathrm{Fe}(\mathrm{Si})$ crystals are formed [6], while $\mathrm{Nb}$ reduces crystal growth rate [7].

Since functional properties are highly dependent on microstructure, detailed understanding of mechanism and kinetics of structural transformations is very important for developing new materials with controlled properties.

* corresponding author; e-mail:

dminic@ffh.bg.ac.rs, drminic@gmail.com

\section{Experimental procedure}

The samples of amorphous $\mathrm{Fe}_{73.5} \mathrm{Cu}_{1} \mathrm{Nb}_{3} \mathrm{Si}_{13.5} \mathrm{~B}_{7}$ alloy were produced using melt spinning method which includes rapid quenching of a melt on a cold rotating disc. The obtained alloy samples exhibited ribbon shape, with thickness of $35 \mu \mathrm{m}$ and width of $2 \mathrm{~cm}$.

$\mathrm{X}$-ray diffraction (XRD) measurements were carried out with PANalytical X'Pert Pro MPD diffractometer and $\mathrm{Co} K_{\alpha}$ radiation operated at $40 \mathrm{kV}$ and $30 \mathrm{~mA}$. Spectra fitting and decomposition were done applying the CONFIT program package, while $\alpha$-iron foil data were used for calibration. Alloy samples for XRD were prepared by repeatedly annealing for $30 \mathrm{~min}$ at successively higher temperatures up to $725^{\circ} \mathrm{C}$, followed by slow cooling to room temperature, at which the measurements were conducted. Scanning electron microscope (SEM) Lyra 3 XMU (TESCAN) and transmission electron microscope (TEM) Philips CM12, with tungsten cathode and $120 \mathrm{kV}$ electron beam, were employed for morphology characterization. Differential scanning calorimetry (DSC) curves were taken with DSC-50 analyzer (Shimadzu, Japan) under nitrogen atmosphere, with a flow rate of $20 \mathrm{~mL} \mathrm{~min}{ }^{-1}$, in temperature range from room temperature to $750{ }^{\circ} \mathrm{C}$, at four constant heating rates (5, 8, 12 and $\left.15{ }^{\circ} \mathrm{C} / \mathrm{min}\right)$. Calibration of the instrument was previously performed for each individual rate. Deconvolution of complex crystallization peaks was conducted using OriginPro 8.5 software applying GaussianLorentzian cross-product function. 


\section{Results and discussion}

XRD patterns of the as-prepared sample show two broad halo peaks at $2 \theta$ of around 52 and $96^{\circ}$ indicating short-range order characteristic of amorphous structure The amorphous structure of the examined samples disappeared after annealing at $475^{\circ} \mathrm{C}$, when crystallization of $\alpha-\mathrm{Fe}(\mathrm{Si})$ phase was observed. Beside $\alpha$ - $\mathrm{Fe}(\mathrm{Si})$ phase, after annealing at $575{ }^{\circ} \mathrm{C}$ small amounts of crystalline $\mathrm{Fe}_{2} \mathrm{~B}$ phase were also observed. Further annealing at higher temperatures led to formation of crystalline $\mathrm{Fe}_{16} \mathrm{Nb}_{6} \mathrm{Si}_{7}$ and $\mathrm{Fe}_{2} \mathrm{Si}$ phases and an increase in content of $\mathrm{Fe}_{2} \mathrm{~B}$ phase, while $\alpha$-Fe $(\mathrm{Si})$ remained the most abundant crystalline phase, Fig. 1.

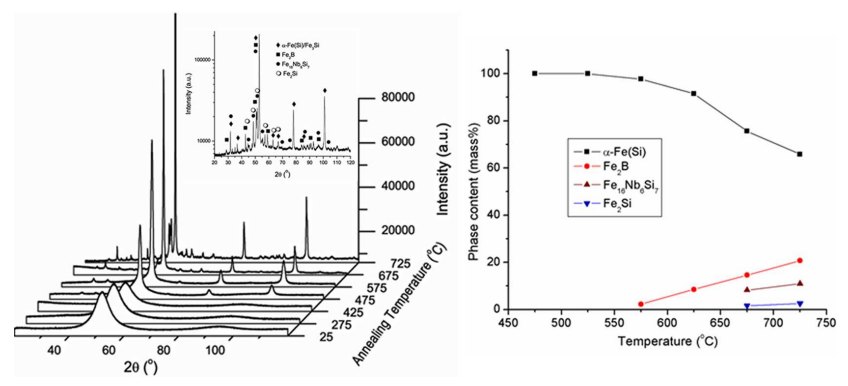

Fig. 1. X-ray diffractograms of alloy samples successively annealed at different temperatures (left) and corresponding phase content (right).

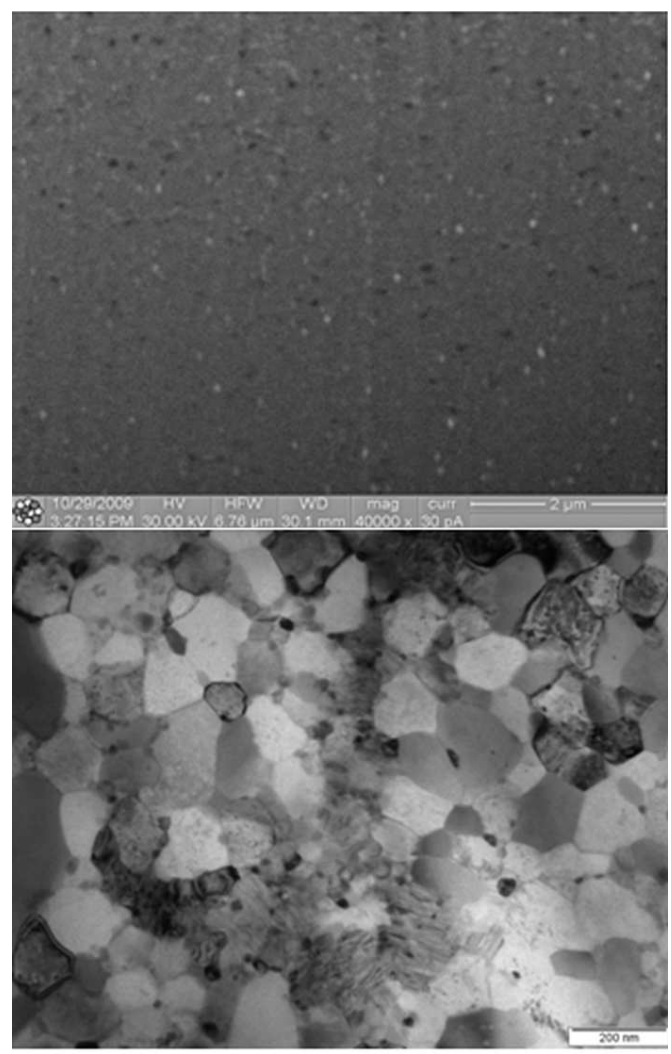

Fig. 2. Morphology characterization: SEM image of alloy sample annealed at $700{ }^{\circ} \mathrm{C}$ (top), TEM image of alloy sample annealed at $725^{\circ} \mathrm{C}$ (bottom).
Results of phase composition from XRD data was correlated with the Mössbauer spectroscopy measurements [8] to resolve the crystallization process. In addition to phases detected in XRD, the Mössbauer spectroscopy also detected some metastable intermediary species, including $\mathrm{Fe}_{3} \mathrm{~B}, \mathrm{FeB}$ and $\mathrm{Fe}_{5} \mathrm{SiB}_{2}$, due to small crystallites, which yielded too weak and broad signals in XRD.

Texture coefficients, determined according to procedure in Ref. [9] obtained for $\alpha$-Fe(Si) phase revealed dominance of (220) plane in comparison with other planes, while increase in contribution of (002) plane with increase in annealing temperature was observed for $\mathrm{Fe}_{2} \mathrm{~B}$ phase. This is consistent with one-dimensional growth of both phases, caused by impingement effect.

Examination of the morphology of the surface and cross-section of the thermally treated samples, using TEM and SEM, showed granulated structure, consisting of several different phases, with diameter in the range from 10 to $1000 \mathrm{~nm}$. Irregular shape of crystalline grains can also be observed, Fig. 2, which originated from merging of neighboring grains of the same phase and from impingement effects, which occurred during the crystal growth.
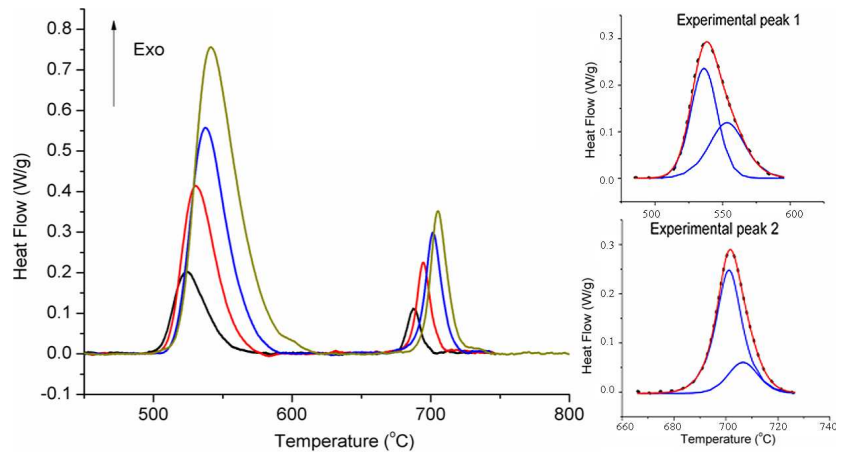

Fig. 3. DSC curves at heating rates of 5, 8, 12 and $15{ }^{\circ} \mathrm{C} \mathrm{min}^{-1}$ with example of peak deconvolution.

Thermal analysis was used to investigate the mechanism and kinetics of crystallization of individual phases. Study of thermal stability of amorphous $\mathrm{Fe}_{73.5} \mathrm{Cu}_{1} \mathrm{Nb}_{3} \mathrm{Si}_{13.5} \mathrm{~B}_{7}$ alloy showed that the alloy was stable up to around $500{ }^{\circ} \mathrm{C}$, when stepwise process of thermal stabilization occurred, exhibiting two clearly separated exothermic peaks corresponding to crystallization, Fig. 3.

Application of the Vyazovkin isoconversional method [10, 11] to experimental peaks from DSC curves revealed significant change in value of apparent activation energy with conversion degree, Fig. 4a. This indicates that processes manifested by distinct exothermic peaks were complex involving more than one crystallization step provoked by crystallization of different phases. In order to examine the kinetics of crystallization in detail, complex crystallization peaks were deconvoluted into two individual steps each, Fig. 3. According to phase composition determined using XRD 

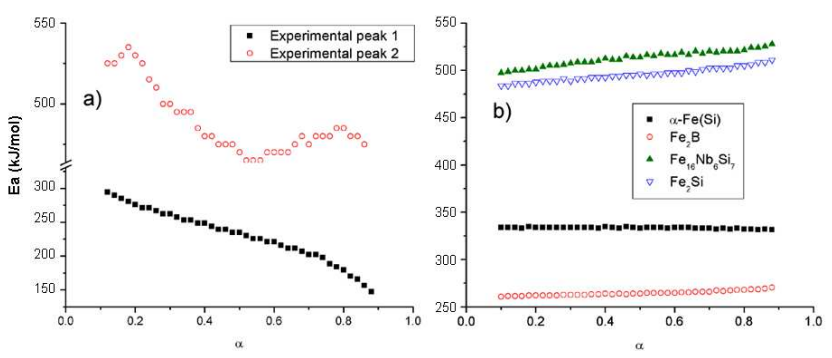

Fig. 4. Values of activation energy obtained for complex experimental crystallization peaks (a), and for crystallization of individual phases (b).

and Mössbauer spectroscopy, individual crystallization steps were ascribed to formation of $\alpha-\mathrm{Fe}(\mathrm{Si}), \mathrm{Fe}_{2} \mathrm{~B}$, $\mathrm{Fe}_{16} \mathrm{Nb}_{6} \mathrm{Si}_{7}$ and $\mathrm{Fe}_{2} \mathrm{Si}$ phase, respectively. The overall values of kinetic parameters, obtained by the Kissinger method [12] are presented in the Table.
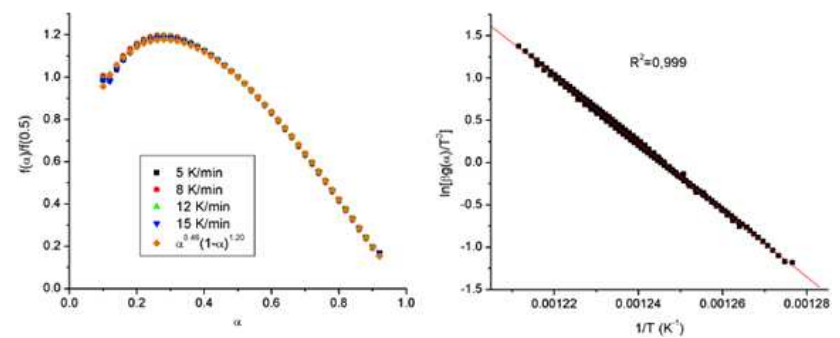

Fig. 5. Master plot (left) and Perez-Maqueda (right) plots - example shown for crystallization of $\alpha-\mathrm{Fe}(\mathrm{Si})$ phase.

\section{TABLE}

Kinetic parameters of individual crystallization steps.

\begin{tabular}{c|c|c|c|c}
\hline \hline & $\alpha-\mathrm{Fe}(\mathrm{Si})$ & $\mathrm{Fe}_{2} \mathrm{~B}$ & $\mathrm{Fe}_{16} \mathrm{Nb}_{6} \mathrm{Si}_{7}$ & $\mathrm{Fe}_{2} \mathrm{Si}$ \\
\hline \multicolumn{5}{c}{ the Kissinger method } \\
\hline$E_{\mathrm{a}}[\mathrm{kJ} / \mathrm{mol}]$ & $335 \pm 7$ & $259 \pm 22$ & $491 \pm 14$ & $474 \pm 28$ \\
\hline $\ln A\left[\mathrm{~min}^{-1}\right]$ & $49 \pm 1$ & $37 \pm 3$ & $60 \pm 2$ & $58 \pm 5$ \\
\hline \multicolumn{5}{c}{ the Vyazovkin isoconversional method (average) } \\
\hline$E_{\mathrm{a}}[\mathrm{kJ} / \mathrm{mol}]$ & $333 \pm 1$ & $264 \pm 1$ & $513 \pm 1$ & $496 \pm 1$ \\
\hline$f(\alpha)$ & $\alpha^{0.46}(1-\alpha)^{1.2}$ & $\alpha^{0.51}(1-\alpha)^{1.3}$ & $\alpha^{1.0}(1-\alpha)^{1.4}$ & $\alpha^{0.60}(1-\alpha)^{1.1}$
\end{tabular}

Effective values of activation energy, which are almost constant with the progress of crystallization, Fig. 4b, suggest that the individual deconvoluted steps correspond to single-step processes. Since the rate of solid-state process is determined by the Arrhenius parameters (activation energy and pre-exponential factor) and conversion function [13] kinetic description of crystallization requires determination of these parameters for each individual crystallization step. The Arrhenius parameters and the conversion function form the kinetic triplet which can be used to predict the stability of the alloy and the kinetics of crystallization in different temperature regions.

Conversion functions for all crystallization steps, according to the Malek [14] method, correspond to twoparameter form of the Sesták-Berggren model, the Table. Master plot and the Perez-Maqueda criteria [15, 16] were used to verify the correct form of the conversion function, Fig. 5.

Using the values of the kinetic triplet for $\alpha$-Fe $(\mathrm{Si})$ phase, values of lifetime $\left(t_{0.05}\right)$ at different temperatures were calculated [17]. We found very high stability against crystallization at room temperature $\left(t_{0.05}=\right.$ $2.2 \times 10^{30}$ years), with abrupt decrease to the value of less than $5 \mathrm{~min}$ at the temperature of the onset of crystallization.

Collisions of growing grains, observed in TEM, of individual phases provoke impingement effect which was investigated using the dependence $\mathrm{d} \alpha / \mathrm{d} t=f(\alpha)$, based on the value of transformation-rate maxima $\left(\alpha_{\mathrm{p}}\right)$ [18]. For all crystallization steps, $\alpha_{\mathrm{p}}=0.5$ was observed suggesting anisotropic growth being the prevailing type of impingement.

\section{Conclusion}

Thermal stabilization of amorphous $\mathrm{Fe}_{73.5} \mathrm{Cu}_{1} \mathrm{Nb}_{3} \mathrm{Si}_{13.5} \mathrm{~B}_{7}$ alloy, which occurred after annealing at $475^{\circ} \mathrm{C}$ includes crystallization of different iron-based phases and exhibits complex peaks in DSC curves. Deconvolution of complex experimental DSC peaks, in correlation with microstructure characterization techniques (XRD, Mössbauer spectroscopy, TEM, SEM), allows the determination of the mechanism and the kinetics of crystallization, corresponding to formation of individual crystalline phases, and prediction of stability of the alloy against thermally induced crystallization. 


\section{Acknowledgments}

This research was supported by the Ministry of Education and Science of Serbia, under the Project 172057, by grant No. GAP108/11/1350 of the Grant Agency of the Czech Republic.

This work was realized in CEITEC - Central European Institute of Technology with research infrastructure supported by the project CZ.1.05/1.1.00/02.0068 financed from European Regional Development Fund.

\section{References}

[1] A.K. Panda, M. Manimaran, A. Mitra, S. Basu, Appl. Surf. Sci. 235, 475 (2004).

[2] J. Shen, Q. Chen, J. Sun, H. Fan, G. Wang, Appl. Phys. Lett. 86, 151907 (2005).

[3] C. Suryanarayana, A. Inoue, Int. Mater. Rev. 58, 131 (2013).

[4] Y. Yoshizawa, S. Oguma, K. Yamauchi, J. Appl. Phys. 64, 6044 (1988).

[5] T. Kulik, J. Non-Cryst. Solids 287, 145 (2001).

[6] K. Hono, D.H. Ping, M. Onhuma, H. Onodera, Acta Mater. 47, 997 (1999).
[7] Y.R. Zhang, R.V. Ramanujan, J. Alloys Comp. 403, 197 (2005).

[8] V.A. Blagojević, M. Vasić, B. David, D.M. Minić, N. Pizúrová, T. Žák, D.M. Minić, Mater. Chem. Phys. 145, 12 (2014).

[9] G.B. Harris, Philos. Mag. 43, 113 (1952).

[10] S. Vyazovkin, J. Comput. Chem. 18, 393 (1997).

[11] S. Vyazovkin, J. Comput. Chem. 22, 178 (2001).

[12] H.E. Kissinger, Anal. Chem. 29, 1702 (1957).

[13] S. Vyazovkin, Thermochim. Acta 355, 155 (2000).

[14] J. Málek, Thermochim. Acta 355, 239 (2000).

[15] J.F. Gotor, M.J. Criado, J. Málek, N. Koga, J. Phys. Chem. A 104, 10777 (2000).

[16] A.L. Perez-Maqueda, M.J. Criado, J.F. Gotor, J. Malék, J. Phys. Chem. A 106, 2862 (2002).

[17] S. Vyazovkin, J. Therm. Anal. Calorim. 83, 45 (2006).

[18] F. Liu, S.J. Song, F. Sommer, E.J. Mittemeijer, Acta Mater. 57, 6176 (2009). 